\title{
Emergence of multidrug-resistant and -hypervirulent Streptococcus agalactiae in Bulgarian patients
}

\author{
Raina Tzvetanova Gergova (), Adile Muhrarova (D), Virna Maria Tsitou (), Ivan Mitov (D)
}

Department of Medical Microbiology, Faculty of Medicine, Medical University of Sofia, Sofia, Bulgaria

To the Editor,

Group B Streptococcus (GBS) (Streptococcus agalactiae) is the leading etiological agent of neonatal meningitis and sepsis but also causes soft-tissue and urogenital infections. ${ }^{1}$ In streptococcal infections complicated by allergy or poor therapeutic response to penicillin, the first alternative choice is macrolides. ${ }^{1,2}$ The rate of macrolide resistance worldwide has increased recently, sometimes in combination with lincosamide resistance in GBS. ${ }^{2}$ The most common serotype-specific antigens for human GBS isolates are Ia, Ib, II, III, and V. ${ }^{3}$ A hypervirulent clone of GBS serotype III that causes invasive disease, pregnancy-associated infections, and urinary tract infections emerged in Hong Kong between 1993-2012. ${ }^{4}$ In 2018-2019, 107 nonduplicate GBS strains were isolated from 792 Bulgarian patients aged between 22-68 years: group I patients ( $\mathrm{n}=93$ ) had genital secretions (vaginal and prostate fluid samples), and group II patients $(\mathrm{n}=14)$ urinal samples (Table 1). Antimicrobial susceptibility testing to 5 agents was based on minimum inhibitory concentration (MIC) according to the European Committee on Antimicrobial Susceptibility Testing, version 10.0, 2020 criteria (http://www.eucast.org). Capsular serotypes Ia, Ib, II, III, IV, V, VI, VII, and VIII were detected by multiplex polymerase chain reaction ${ }^{5}$, with a denaturation step for 5 minutes at $95^{\circ} \mathrm{C}$, followed by 30 cycles of $95^{\circ} \mathrm{C}$ for 30 seconds, $59^{\circ} \mathrm{C}$ for 30 seconds, $72^{\circ} \mathrm{C}$ for 60 seconds, and a final extension of $72^{\circ} \mathrm{C}$ for 5 minutes.

All the collected GBS were susceptible to penicillin but with an $\mathrm{MIC}_{90}$ of $0.12 \mathrm{mg} / \mathrm{L}$, near the limit value $(0.25 \mathrm{mg} / \mathrm{L}) ; 58.88 \%$ showed resistance to erythromycin, and $15.89 \%$ showed resistance to clindamycin, both with an $\mathrm{MIC}_{90}$ of $2 \mathrm{mg} / \mathrm{L}$. Levofloxacin resistance occurred in $10.28 \%$ of the isolates $\left(\mathrm{MICs}_{90}\right.$ of $\left.3 \mathrm{mg} / \mathrm{L}\right)$; it occurred in the urinal samples (42.86\%) more than in the genital ones $(5.38 \% ; P$ $<0.05$ ), probably because of frequent quinolone use in uroinfections. The tetracycline resistance rate of all tested isolates was $94.62 \%$ with an $\mathrm{MICs}_{90}>256 \mathrm{mg} / \mathrm{L}$. Multidrug resistance (MDR) to at least 3 classes of drugs occurred in $22.22 \%$ of the GBS strains. The most prevalent serotypes were Ia and V, followed by serotype III. Hypervirulent serotype III, causing invasive infections in other countries, ${ }^{4}$

TABLE 1. Distribution of capsular types in 107 studied isolates GBS according clinical diagnoses and the source of samples

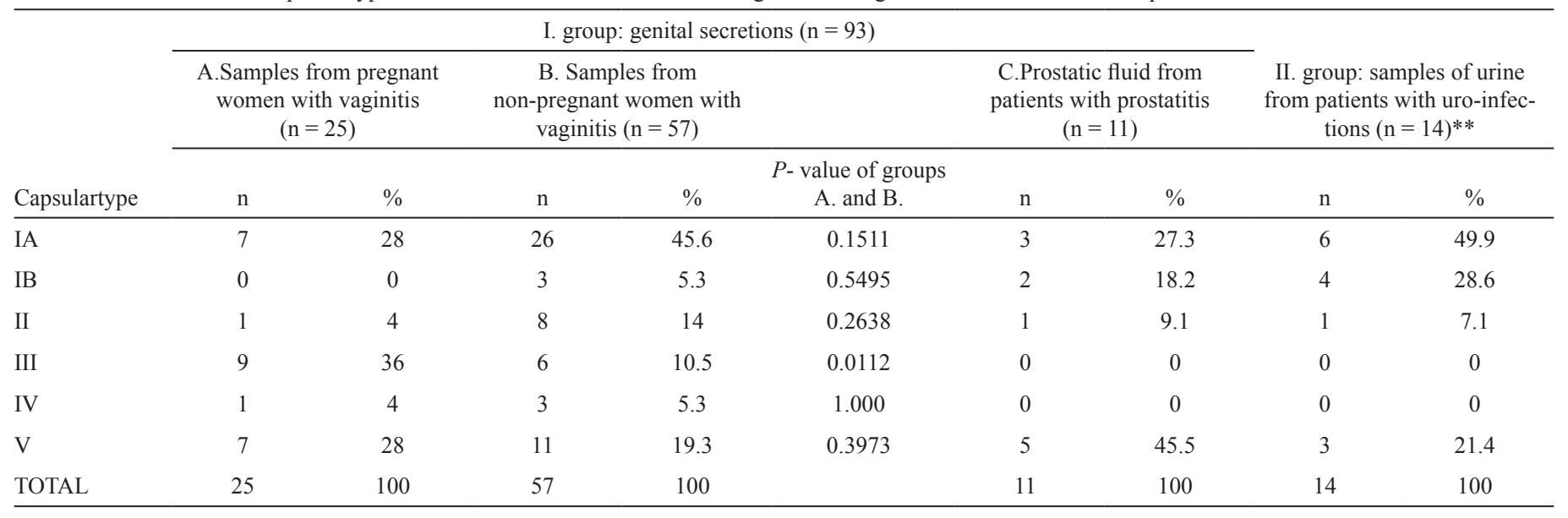

*Underlined text considered to be statistically significant; **P value was not calculated because small number of samples were presented.

Address for Correspondence: Raina Tzvetanova Gergova, Department of Medical Microbiology, Faculty of Medicine, Medical University of Sofia, Sofia, Bulgaria e-mail: rtgergova@gmail.com

Received: July 16, 2020 Accepted: January 17, 2021 • DOI: 10.5152/balkanmedj.2021.20152

Available at www.balkanmedicaljournal.org

ORCID iDs of the authors: R.T.G. 0000-0003-3605-6447; A.M.. 0000-0001-9111-991X; V.M.T. 0000-0003-08864498; I.M. 0000-0002-8417-0968.

Cite this article as:

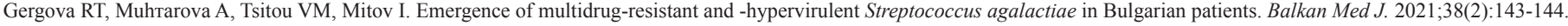

Copyright@Author(s) - Available online at http://balkanmedicaljournal.org/ 
was identified in $14.0 \%$ of the Bulgarian GBS isolates. This serotype was isolated more often $(P<0.05)$ from pregnant women with vaginitis $(36.0 \%)$ than from nonpregnant ones $(10.5 \%)$. It was not detected in patients with uroinfection and prostatitis.

To the best of our knowledge, this is the first report of MDR and hypervirulent GBS isolates in Bulgaria with such a high frequency of resistant GBS. Although the conventional antimicrobial agent penicillin was most effective in vitro, the alternative treatment options for patients with allergy or therapeutic failures after the first-line penicillin treatment were unpromising. There is a concerning trend toward the rapid development of macrolide resistance. That reflects on the use of lincosamides, especially in more severe infections, making their therapeutic effect unsafe. ${ }^{2}$ The resistance to tetracyclines was nearly absolute. Quinolone resistance also occurred, albeit to a lesser extent but often in MDR isolates. Alarmingly, over $22 \%$ of the tested Bulgarian GBS isolates were MDR, and at least 3 antimicrobial classes considered appropriate for treatment are becoming ineffective. In addition, $14.0 \%$ of all GBS isolates and $36 \%$ of those from pregnant women harbored genes encoding the hypervirulent serotype III, which increases the risk of invasive streptococcal infections. To prevent streptococcal MDR from increasing, macrolides, lincosamides, tetracyclines, and quinolones must be used only after antimicrobial susceptibility testing. A correct and timely GBS screening in pregnant women can facilitate proper treatment to reduce maternal and perinatal GBS disease.
Acknowledgments: This work is supported by the Bulgarian Ministry of Education and Science under the National Program for Research "Young Scientists and Postdoctoral Students (AM)", Medical University Sofia.

Author contributions: Concept - R.T.G., A.M.; Design - R.T.G., A.M., V.M.T.; Supervision - R.T.G., I.M.; Resources - R.T.G., I.M.; Materials - R.T.G., A.M., V.M.T.; Data Collection and/or Processing - R.T.G., A.M., V.M.T.; Analysis and/or Interpretation - R.T.G., A.M., V.M.T.; Literature Review - R.T.G., A.M.; Writing - R.T.G., A.M.; Critical Review - R.T.G., A.M., I.V.

Conflict of Interest: The authors have no conflicts of interest to declare.

Funding: The authors declared that this study has received no financial support.

\section{REFERENCES}

1. Raabe V, Shane A. Group B Streptococcus (Streptococcus agalactiae). GramPositive Pathogens, Chapter 14.2019;228-238. [Crossref]

2. Gizachew M, Tiruneh M, Moges F, Adefris M, Tigabu Z, Tessema B. Streptococcus agalactiae from Ethiopian pregnant women; prevalence, associated factors and antimicrobial resistance: alarming for prophylaxis. Ann Clin Microbiol Antimicrob. 2019;18(1):3. [Crossref]

3. Gizachew M, Tiruneh M, Moges F, Adefris M, Tigabu Z, Tessema B. Molecular characterization of Streptococcus agalactiae isolated from pregnant women and newborns at the University of Gondar Comprehensive Specialized Hospital, Northwest Ethiopia. BMC Infect Dis. 2020;20(1):35. [Crossref]

4. Ip M, Ang I, Fung K, Liyanapathirana V, Luo MJ, Lai R. Hypervirulent clone of group B Streptococcus serotype III sequence type 283, Hong Kong, 1993-2012. Emerg Infect Dis. 2016;22(10):1800-1803. [Crossref]

5. Poyart C, Tazi A, Réglier-Poupet H, et al. Multiplex PCR assay for rapid and accurate capsular typing of group B streptococci. J Clin Microbiol. 2007;45(6):1985-1988. [Crossref] 